\title{
Thermographic Control of Pediatric Dental Patients During the SARS-CoV-2 Pandemics Using Smartphones
}

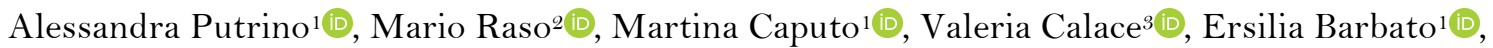 \\ Gabriella Galluccion ${ }^{10}$
}

'Department of Oral and Maxillofacial Sciences, Sapienza University of Rome, Rome, Italy.

${ }^{2}$ Ministry of Defence, Italian Society for Applied and Industrial Mathematics (SIMAI) member, Rome, Italy.

${ }^{3}$ Orthodontic private practice, Rome, Italy.

Correspondence: Alessandra Putrino, Department of Oral and Maxillofacial Sciences, Unit of Orthodontics, Sapienza University of Rome, Italy. E-mail: alessandra.putrino@gmail.com

Academic Editor: Alessandro Leite Cavalcanti

Received: 21 November 2020 / Review: 22 February 2021 / Accepted: 15 March 2021

How to cite: Putrino A, Raso M, Caputo M, Calace V, Barbato E, Galluccio G. Thermographic control of pediatric dental patients during the sars-cov-2 pandemics using smartphones. Pesqui Bras Odontopediatria Clín Integr. 2021; $21:$ e0248. https://doi.org/10.1590/pboci.2021.099

\begin{abstract}
Objective: To evaluate the reliability of infrared (IR) thermal camera connected to smartphones, already used in medicine for diagnostic purposes, as an easy tool for access screening to pediatric dentistry services. Material and Methods: After the preventive telephone triage, thirty orthodontic patients (7-13 years) underwent temperature measurement in the office with two no-contact IR devices: forehead digital thermometer and thermal-camera connected to a smartphone (reference areas: forehead, inner canthi, ears). Measurements were compared and differences were statistically investigated with $\mathrm{T}$ student's test $(\mathrm{p}<0.01)$. Results: Forehead digital thermometer temperatures were superimposable to those recorded in ear areas and inner canthi with the thermal camera connected to a smartphone. Differences were not statistically significant even in comparison between the sexes. Forehead temperature values detected with a thermal camera are lower than those detected with a digital forehead thermometer. Conclusion: Thermal camera on a smartphone could be reliable in measuring body temperature. Mobile thermographic values of ears and inner canthi areas can be used as an alternative to forehead digital thermometer measurements. Further applications in pediatric dentistry of thermography on smartphones should be examined.
\end{abstract}

Keywords: Differential Thermal Analysis; SARS-CoV-2; Smartphone; Body Temperature; Fever. 


\section{Introduction}

Since the beginning of the pandemic, as knowledge and experience on the novel Coronavirus evolved, national and international health institutions provided precautionary standards to follow to ensure safe access to patients in hospitals, medical and dental practices [1,2].

Dental activity during the lockdown was limited to emergency management. In particular, orthodontic checks in pediatric patients were often carried out remotely [3]. During dental emergency management and later, once the routine dental activity was resumed, among the protective measures taken in addition to telephone triage and the use of all personal protective devices (face mask, gloves, shoe covers, hair cap), great relevance was given to the measurement of body temperature. A body temperature above $37.5^{\circ} \mathrm{C}$ is considered one of the potential symptoms of COVID-19. Although many SARS-CoV2 positive subjects are asymptomatic, the fever, a common symptom of viral infections in general, should be considered one of the first patient records to be monitored $[4,5]$.

Following the recommendations issued by national health authorities and clinical experience during the first year of pandemic, protocols for body temperature screening emerged [6,7]. The reliability of the body temperature measurement depends on different factors, such as the measuring instrument, the body site, the procedure, the environmental conditions, and the measurand conditions [8].

Body temperature is usually measured with digital thermometers. During the pandemic, the problem of maintaining a safe distance (according to the WHO, estimated to be around 1 meter) and the problem of disinfecting the instruments' surfaces used in this type of screening immediately arose to avoid the spread of contagion. For this reason, the use of infrared digital thermometers that work without direct contact on the skin (NCIT or non-contact infra-red thermometers) and other contactless devices such as infrared thermal imaging cameras (IR-TIC) and infrared thermal scanners have been recommended [8-11].

Thermal imaging cameras and scanners are considered more reliable and safe devices than infrared digital thermometers when they detect body temperature at the inner canthi, forehead and auricular area because the procedure is standard and errors related to the operator have been considered not relevant $[12,13]$. The unique factor that can influence the reliability of non-contact infrared measurements comes from the environmental conditions. The expanded uncertainty ranges between $0.40^{\circ} \mathrm{C}$ (for a subject at rest in an indoor environment and after an adequate stabilization time of $10-12$ minutes) and $0.62^{\circ} \mathrm{C}$ (for a subject immediately after marching in an outdoor environment and without thermal stabilization) [14]. Both measurements with an infrared digital thermometer and with thermal imaging cameras or scanners, therefore, require a constant ambient temperature of around $18-21^{\circ} \mathrm{C}$ with a humidity level of no more than $50 \%$ and no less than $30 \%$. These rules, in addition to an adequate acclimatization time of the subject at rest without jackets and clothing or accessories that cover the face (including the mask), lead to a realistic measurement of body temperature [11].

All objects, including human bodies, emit electromagnetic radiation (thermal radiation). The wavelength of radiation emitted depends on the temperature of the objects. Most of the radiation emitted by humans is in the infrared region, mainly at the wavelength of 12 microns. The wavelength of infrared radiation is between 0.75 to 1000 micron ( 1 micron $=10^{-6}$ meters). The amount of thermal radiation emitted by an object or body depends on its surface temperature, area and characteristics. Warmer objects emit more thermal radiation than cooler ones. The original meaning of thermography is 'the technique for making a thermogram'. 
The complete definition of thermography is 'a technique wherein an infrared camera photographically portrays the body's surface temperature, based on self-emanating infrared radiations' [15].

Considering the need for adequate stabilization of the subject before starting to measure his temperature, a double-step measurement protocol is advisable. This procedure consists of a first measurement, a non-contact body temperature device, and a second step, with a further no contact body temperature measurement when the measured value falls within the uncertainty zone. The application of these rules reduces false negatives and, consequently, the risk associated with unreliable screening [7].

One of the main limitations of thermography, which is likely to run into without adequate knowledge of this technology, is not providing the experimental field in which to perform thermographic measurements of a "blackbody". A blackbody is an idealized body (with a known emissivity of 1) that fully absorbs impinging electromagnetic radiation of any wavelength. Neither reflection nor transmission occurs on it. A black body radiates at every wavelength the maximum possible energy for all possible emitters. The radiation density is independent of angles. Blackbodies simulators have an emissivity ranging from 0.9 to 0.99 . They are used as an optical reference source to obtain more accurate measurements providing a reference temperature in the field of view of the thermal imaging camera. The potential for drift or detection errors during measurements is further reduced and it allows a higher performance than the normal temperature measurement with a digital thermometer $[11,13,14]$.

A thermal imaging camera (or thermal camera) is a non-contact device that detects infrared energy (heat) and converts it into a visual image. A thermal camera is made up of a lens, a thermal sensor, a detector, processing electronics, and a mechanical housing. The lens focuses infrared energy on the sensor. The sensor can come in a variety of pixel configurations, from $80 \times 60$ to $1280 \times 1024$ pixels or more. The pixel configuration determines the resolution of the camera [16].

Thermal camera resolutions are low compared to visible visible light cameras because thermal detectors need to an sense energy that has much larger wavelengths than visible light, requiring each sensor element to be significantly larger. As a result, a thermal camera usually has a much lower resolution (fewer pixels) than visible sensors of the same mechanical size. Detectors in an infrared camera capture a particular range of invisible energy emission (700-1000 $\mathrm{nm}$ ) and then express each heat value (or wavelength) through a set of corresponding colors. The resulting image is called a thermogram or thermography [17].

Thermal cameras are divided into two types depending on the type of detector: cooled or uncooled. Cooled detectors deliver better image quality and precision, while uncooled detectors are less precise and less expensive. Cooled infrared detectors must be coupled with cryogenic coolers to lower the detector temperature to cryogenic temperatures and reduce the heat-induced noise to a level lower than that of the signal emitted by the scene. Uncooled image detectors do not require cryogenic cooling. They are designed using a microbolometer device - a special type of bolometer that is sensitive to infrared radiation [15].

The exposure settings, also known as shutter speed or integration time, vary from device to device and their values depend on the type of detector. Exposure setting values in thermal cameras commonly vary between 8 and 12 milliseconds. Other important features that differentiate thermal cameras from each other are the range, the field of view or FOV, the spectral range, the thermal sensitivity and the focus. The range is the entire span of temperatures the camera is calibrated to and capable of measuring [18].

Some cameras have multiple ranges to measure a wider span of temperatures more accurately. Field of View is determined by the camera lens and is the extent of a scene that the camera will see at any given 
moment. A lens with a wide-angle FOV ( $45^{\circ}$ or higher) is necessary for work being done close-up. A telephoto lens $\left(12^{\circ}\right.$ or $\left.6^{\circ}\right)$ is required for long-distance work. The spectral range is the range of wavelengths that the sensor in the camera detects, measured in micrometers $(\mu \mathrm{m})$. Almost all thermal cameras have a spectral range of $8-14 \mu \mathrm{m}$. A spectral range of $3-5 \mu \mathrm{m}$ is typical of gas detection cameras (propane, methane and butane detectors). Thermal sensitivity or Noise Equivalent Temperature Difference (NETD) describes the smallest temperature difference detectable with the camera. The lower the number, the better the thermal sensitivity of the infrared system. The standard NETD is around $30-50^{\circ} \mathrm{C}$. The focus may be fixed, manual or automatic. Entry level cameras have fixed focus, and high-performance cameras have either manual or automatic focus $[19,20]$.

Thermography is based on the amount of blood circulation at the different layers of the skin. All the situations that affect the blood flow result in abnormal temperature distribution useful to help in the diagnosis of many pathological conditions when assessed by thermographic tools [12,13].

Thermography has various applications in assessing many dental conditions: temporomandibular joint disorders, chronic orofacial pain, inferior alveolar nerve deficit, pulpal thermal damages, herpes labialis prodromal phase, surgery of impacted teeth [21-24]. Among the various types of thermographic analysis (infrared, liquid crystals, microwave), infrared thermography is the most used in the medical and dental field. Infrared thermography is a diagnostic method widely used also in the pediatric field. The usefulness of thermographic evaluation in the pediatric clinical practice was evaluated to manage fractures, musculoskeletal injuries, diagnosis of acute undifferentiated limp and microvascular dysfunction [25-30].

Thermographic studies were also conducted on pediatric samples to detect body temperature, highlighting a basal difference between the two sexes [31,32]. The advantages of dental and pediatric thermographic evaluation are its noninvasivity (it is a no-contact examination), the minimal time required (2-3 minutes), the easy seating examination, the real-time application, the detection of temperature differences around $0.05^{\circ} \mathrm{C}$ for adjacent areas pointed out with different gradient of colours, the easy interpretation of the data. On the other hand, the most commonly described in literature disadvantages on the use of thermography in dentistry and pediatrics are the high price of quality cameras, the need for a reduced angle of view to improve sensitivity and resolution, and the accuracy rate lower than $\pm 2 \%[9,13,24]$. Even if the use of the forehead as a point of body temperature detection with IR-TIC is accepted, the most effective approach considers the inner canthi of eyes (the medial angle or corner of each eye where the upper and lower eyelids meet) the best location and the full-face maximum temperature the best performance while the forehead should be considered as the less accurate location [7,24].

For some time now, there have been IR-TICs on the market recognized for their excellent characteristics in terms of accuracy and sensitivity and at affordable prices that connecting to common smartphones can provide excellent thermographic images also useful for diagnostic purposes [33-35]. This study aimed to evaluate the use of IR-TIC on a smartphone as a reliable device for body temperature measurement in children.

\section{Material and Methods}

Study Design and Sample

In this pilot study, sample size calculation has not been performed. The reduced flux of patients to the orthodontic check-ups, because in a state of preventive quarantine from contact with infected people or because 
with symptoms attributable to infection and awaiting serological test and / or swab, did not allow this phase to reach a large number of observations. The general flat rule to 'use at least 30 subjects or greater to estimate a parameter' described in the rules of thumb for pilot study trial has been applied [36]. Thirty patients between 7 and 13 years of age (14 males and 16 females) presented at different times for our observation in the dental clinic for periodic orthodontic control after having carried out the telephone triage and communicated the body temperature detected at home with a digital forehead thermometer by a parent just before presenting themselves to the appointment.

\section{Data Collection}

The telephone triage of examined patients did not reveal potentially important elements for possible contact with the SARS-CoV-2 (in the last two weeks, no travels to red areas, no contact with people who had been in red areas, no episodes of fever or other symptoms related to COVID-19, no contact with people who had fever or symptoms related to COVID-19, no contact with people who tested positive for COVID-19 or waiting for testing ore testing result for COVID-19). Once the patients entered the dental office, their hands were immediately sanitized with a sodium hypochlorite-based gel. They were provided with a hair cap, shoe covers, and gloves (all disposable devices). When they did not have one, they were given a surgical mask. This personal protective equipment, maintained for the entire time of recording the anamnestic data, was removed (including any eyeglasses) to not influence the skin temperature not less than 10 minutes before taking the thermographic measurements. Since the thermographic test was always carried out before the orthodontic check (to avoid that the dental procedures could influence the subsequent measurements), the protective devices were then put on again by each patient before sitting in the dental chair for the check-up.

The ambient temperature has always been kept around $18-21^{\circ} \mathrm{C}$, the humidity around $30-50 \%$ and the air exchange guaranteed between one patient and another. Measurements were always taken after each patient had acclimatized for about 15 minutes sitting in the empty waiting room, at established temperature and humidity, monitored with a wall-mount temperature/humidity sensor (SRH100, Setra Systems, Inc., Boxborough, MA, USA) without nearby IR radiation sources (no incandescent lighting were used during the examination). A dental assistant detected body temperature measurement for each patient with a forehead NCIT (UX-A-01, BigButterfly). A moment later, one of the orthodontists used an IR-TIC (Seek ${ }^{\mathrm{TM}}$ Thermal CompactPRO, Seek Thermal Inc., Santa Barbara, CA, USA) (Figure 1) connected to a smartphone (Galaxy J5, Samsung, Seoul, South Korea) to take the higher facial temperature at the forehead and inner canthi in frontal view and ear area on both sides in lateral observation.

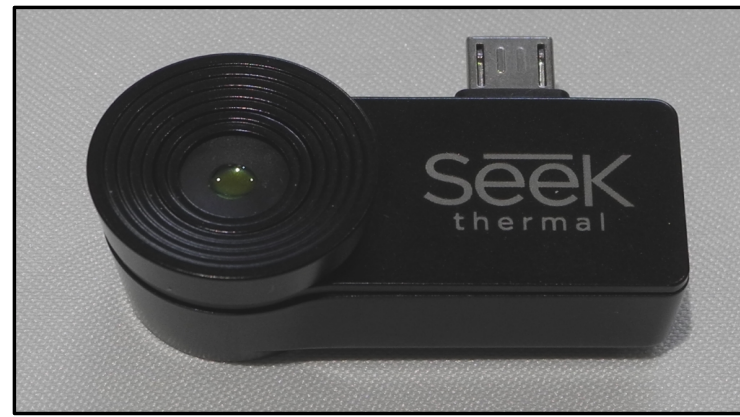

Figure 1. Thermal imaging camera (Seek Thermal Compact Pro) that can be connected to a common smartphone. 
The IR-TIC used for this study has a 320 x 240 thermal sensor, $32^{\circ}$ field of view, a focusable lens, the capability to detect temperatures from $-40^{\circ} \mathrm{C}$ to $330^{\circ} \mathrm{C}$, adjustable emissivity and 548.64 meters of detection distance. The IR-TIC sensor was manually adjusted before each measurement by setting it to the basic ambient temperature measured at that precise moment (and confirmed by the wall mount sensor value). A blackbodycalibrated emitter has been used, too, and it was set to just above normal body temperature to configure the camera filter as suggested by the product manufacturer (Figures 2 and 3 ).

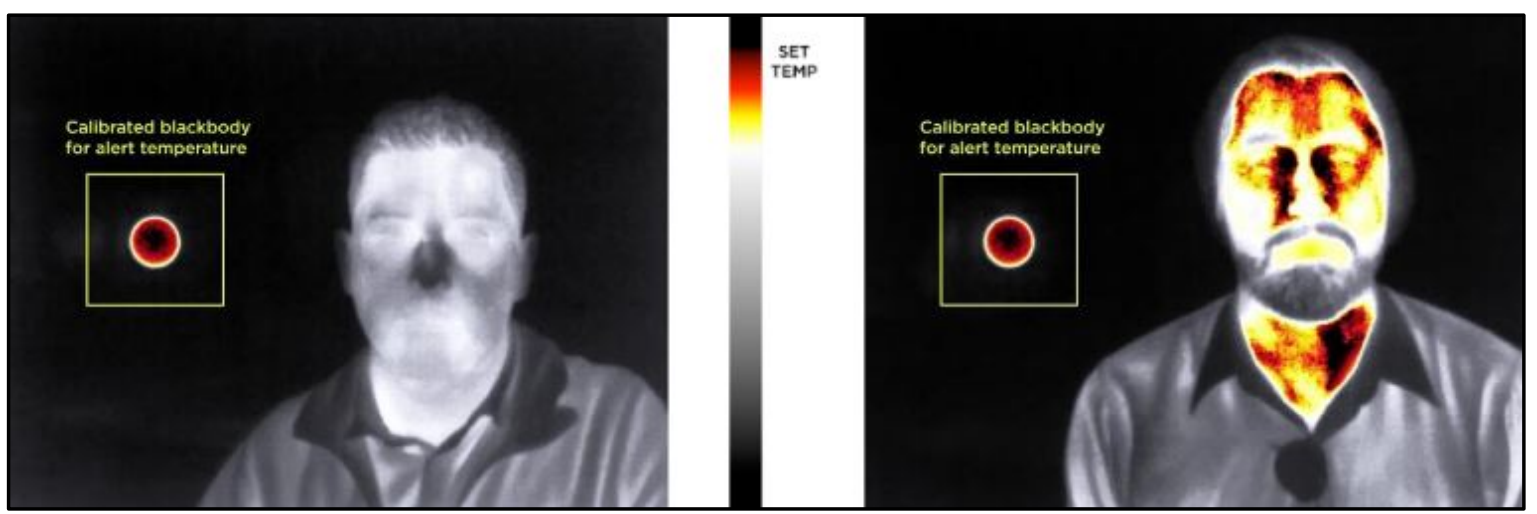

Figure 2. The person on the left is not displayed in color and does not have elevated body temperature (above $36.8^{\circ} \mathrm{C}$ ). The person on the right is displayed in color and has elevated body temperature (Source: Seek Thermal - Elevated Body Temperature Detector App Note v1.0).

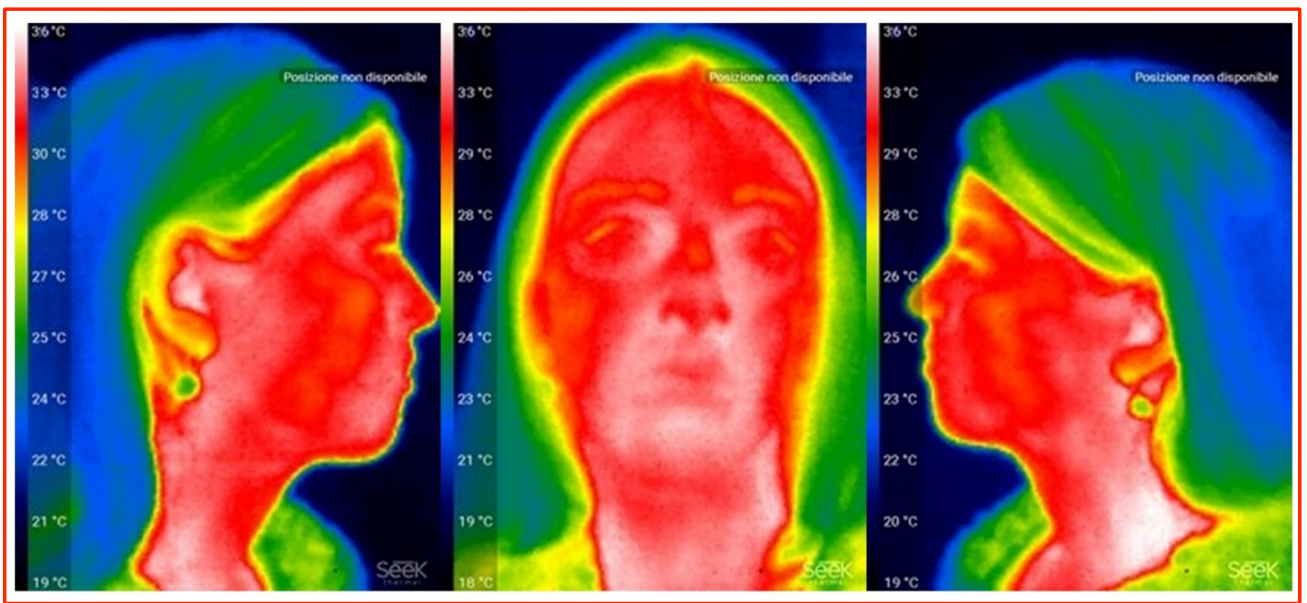

Figure 3. Patient's snapshot of thermal imaging video recording examination, showing the temperatures' values and corresponding graduated colors at the right ear area, in frontal view at the front head and inner canthi, at left ear area.

The definition of the camera lens was also adjusted at the time of detection on each subject's face. To maintain the safety distance of 1 meter, two coloured squares made of plastic adhesive tapes on the floor marked the patient's position (seating) and the operator before the thermal examination. Among the possible ways of representing the thermographic image, from the app's settings connected to the thermal camera, the palette called "spectra" has been selected because it has more accurate and differentiates colorimetric scale than the others available. A short video of 50 seconds was recorded and the higher temperatures at different points 
(forehead, inner canthi and both ears areas) were taken as final measurement. All patients did not have acute or chronic inflammatory situations sensitive to the thermographic detection of facial temperature and were not undergoing pharmacological treatment. The temperature values detected with the different devices were listed in an electronic sheet (Microsoft Excel 2018; Microsoft Corp., Albuquerque, New Mexico, USA) where the patient identity was hidden, representing them by a number from 1 to 30 and indicating age, sex and type of orthodontic therapy.

\section{Data Analysis}

The data collected were subjected to comparative measurements and to statistical analysis with the $\mathrm{T}$ Student's test $(\mathrm{p}<0.01)$ (Microsoft Excel 2018; Microsoft Corp., Albuquerque, New Mexico, USA).

\section{Ethical Clearance}

Informed consent for this study has been expressed by all their parents, knowing their data and thermal images would be treated and disclosed anonymously. The current Italian Regulation of the Ethics Committee of the Higher Institute of Health (Istituto Superiore di Sanità) establishes the ethical aspects that need evaluation, approval and monitoring of trial protocols relate to epidemiological, evaluation and medicalsocial projects when personal data are not anonymised. In accordance with this regulation, in this study, the personal data of patients were anonymized.

\section{Results}

All the patients had a body temperature below $36.8^{\circ} \mathrm{C}$ regardless of the measuring device. The highest values $\left(36.6^{\circ} \mathrm{C}\right)$, both in the right ear areas with the IR-TIC, have been detected on two female patients of 7 and 8 years, respectively. The lowest value $\left(32.7^{\circ} \mathrm{C}\right)$ has been detected in a male patient 13 years old and during the forehead measurement with the IR-TIC (Table 1).

The student's T-test was applied to both the total sample and in the sample divided according to the sex of the patients. The comparison between the means of the total sample for the forehead temperature values detected with NCIT and IR-TIC (T Forehead-NCIT and T Forehead-IR-TIC, respectively) is statistically significant $(\mathrm{p}<0.01)$. The comparison between the $\mathrm{T}$ Forehead-NCIT means values of the total sample and the temperature mean values detected with the IR-TIC at the right and left ears areas (T ear Right-IR-TIC and T ear Left-IR-TIC respectively) are not statistically significant as for the comparison with the mean values of both the ears areas ( $\mathrm{T}$ ears-IR-TIC) and inner canthi ( $\mathrm{T}$ inner canthi-IR-TIC) $(\mathrm{p}<0.01)$. The comparisons between the $\mathrm{T}$ Forehead-IR-TIC and T ear Right-IR-TIC, T ear Left-IR-TIC, T ears-IR-TIC and T inner canthi-IR-TIC are statistically significant $(\mathrm{p}<0.01)$ (Table 2$)$.

By subdividing the general sample based on the sex of patients (16 F and $14 \mathrm{M}$ ), the Student's T-test was performed to assess whether sex influenced in a statistically significant way the temperatures detected. The comparison between the means of the T Forehead-NCIT, T Forehead-IR-TIC, T ear Right-IR-TIC, T ear Left-IR-TIC, T ears-IR-TIC and T inner canthi-IR-TIC, in females and male patients are not statistically significant for both the subgroups $(\mathrm{p}<0.01)$ (Table 3$)$. 
Table 1. Patients' data (age, sex, type of orthodontic treatment) and related temperature values expressed in Celsius.

\begin{tabular}{|c|c|c|c|c|c|c|c|c|c|c|}
\hline Patient & Age & Sex & $\begin{array}{l}\text { Orthodontic } \\
\text { Therapy }\end{array}$ & $\begin{array}{l}\text { T Forehead with } \\
\text { NCIT at Home }\end{array}$ & $\begin{array}{l}\text { T Forehead with } \\
\text { NCIT at D.O. }\end{array}$ & $\begin{array}{l}\text { T Forehead } \\
\text { with IR-TIC }\end{array}$ & $\begin{array}{l}\text { T Right Ear } \\
\text { with IR-TIC }\end{array}$ & $\begin{array}{l}\text { T Left Ear } \\
\text { with IR-TIC }\end{array}$ & $\begin{array}{l}\text { Mean Values of } t \text { in Both } \\
\text { Ears with IR-TIC }\end{array}$ & $\begin{array}{c}\text { T Inner } \\
\text { Canthi-IR-TIC }\end{array}$ \\
\hline 1 & 9 & $\mathrm{M}$ & Fixed & 36.2 & 36.1 & 35.0 & 36.2 & 36.3 & 36.2 & 36.3 \\
\hline 2 & 10 & $\mathrm{~F}$ & Mixed & 35.8 & 36.0 & 34.7 & 36.3 & 360 & 36.1 & 36.0 \\
\hline 3 & 13 & $\mathrm{M}$ & Removable & 36.0 & 36.2 & 35.8 & 36.1 & 36.1 & 36.1 & 36.2 \\
\hline 4 & 7 & M & Removable & 35.1 & 35.0 & 33.4 & 35.2 & 35.0 & 35.1 & 35.2 \\
\hline 5 & 11 & $\mathrm{~F}$ & Fixed & 35.6 & 35.1 & 34.0 & 35.5 & 35.4 & 35.4 & 35.5 \\
\hline 6 & 10 & $\mathrm{~F}$ & Fixed & 36.4 & 36.3 & 35.0 & 36.4 & 36.1 & 36.2 & 36.2 \\
\hline 7 & 12 & M & Removable & 34.8 & 34.3 & 34.1 & 34.5 & 34.0 & 34.2 & 34.4 \\
\hline 8 & 9 & $\mathrm{~F}$ & Fixed & 35.7 & 35.8 & 35.5 & 36.0 & 35.8 & 35.9 & 35.7 \\
\hline 9 & 10 & $\mathrm{~F}$ & Mixed & 36.2 & 36.0 & 34.8 & 36.0 & 35.8 & 35.9 & 35.8 \\
\hline 10 & 7 & $\mathrm{~F}$ & Mixed & 36.7 & 36.3 & 35.0 & 36.4 & 36.1 & 36.2 & 36.2 \\
\hline 11 & 8 & $\mathrm{M}$ & Removable & 36.0 & 36.4 & 35.2 & 36.6 & 36.3 & 36.4 & 36.3 \\
\hline 12 & 8 & $\mathrm{~F}$ & Removable & 35.0 & 35.5 & 35.0 & 36.1 & 36.0 & 36.0 & 36.1 \\
\hline 13 & 11 & $\mathrm{~F}$ & Fixed & 35.4 & 35.0 & 33.0 & 35.0 & 35.0 & 35.0 & 35.1 \\
\hline 14 & 10 & $\mathrm{~F}$ & Fixed & 36.3 & 36.1 & 34.0 & 36.3 & 36.1 & 36.2 & 36.0 \\
\hline 15 & 13 & M & Fixed & 34.8 & 34.5 & 32.7 & 34.3 & 34.1 & 34.2 & 34.3 \\
\hline 16 & 9 & $\mathrm{M}$ & Removable & 34.6 & 35.0 & 34.0 & 35.0 & 35.0 & 35.0 & 35.1 \\
\hline 17 & 10 & $\mathrm{~F}$ & Removable & 35.6 & 36.0 & 34.0 & 36.0 & 35.7 & 36.1 & 36.0 \\
\hline 18 & 9 & $\mathrm{M}$ & Fixed & 35.0 & 35.1 & 35.0 & 35.4 & 35.4 & 35.4 & 35.3 \\
\hline 19 & 7 & $\mathrm{~F}$ & Removable & 36.1 & 36.4 & 34.0 & 36.5 & 36.0 & 36.2 & 36.1 \\
\hline 20 & 10 & $\mathrm{M}$ & Mixed & 34.7 & 35.0 & 33.8 & 35.2 & 35.0 & 35.1 & 35.1 \\
\hline 21 & 13 & $\mathrm{M}$ & Fixed & 35.4 & 36.1 & 35.5 & 35.8 & 36.0 & 35.9 & 36.0 \\
\hline 22 & 11 & M & Fixed & 35.6 & 36.0 & 35.0 & 36.3 & 36.0 & 36.1 & 36.2 \\
\hline 23 & 12 & $\mathrm{~F}$ & Fixed & 36.5 & 36.1 & 36.1 & 36.5 & 36.2 & 36.3 & 36.2 \\
\hline 24 & 11 & $\mathrm{~F}$ & Removable & 34.9 & 35.3 & 33.0 & 35.7 & 35.5 & 35.6 & 35.6 \\
\hline 25 & 9 & M & Removable & 35.7 & 36.2 & 34.6 & 36.4 & 36.1 & 36.2 & 36.1 \\
\hline 26 & 8 & $\mathrm{~F}$ & Mixed & 36.4 & 36.0 & 34.4 & 36.5 & 36.3 & 36.4 & 36.2 \\
\hline 27 & 8 & $\mathrm{~F}$ & Removable & 34.9 & 35.1 & 35.0 & 35.2 & 35.2 & 35.2 & 35.1 \\
\hline 28 & 9 & M & Fixed & 35.6 & 36.0 & 35.0 & 36.0 & 36.0 & 36.0 & 36.0 \\
\hline 29 & 9 & $\mathrm{~F}$ & Mixed & 36.2 & 36.0 & 35.3 & 36.3 & 36.1 & 36.2 & 36.1 \\
\hline 30 & 7 & $\mathrm{M}$ & Removable & 36.0 & 36.3 & 35.8 & 36.6 & 36.2 & 36.4 & 36.2 \\
\hline
\end{tabular}

NCIT: No Contact Infrared Thermometer; IR-TIC: Infrared Thermal Imaging Camera. 
Table 2. Comparisons between the Temperature detected at Forehead with no Contact Infrared Thermometer ( $T$ Forehead-NCIT) and Infrared Thermal Imaging Camera (T Forehead-IR-TIC) and Temperature detected with the Infrared Thermal Imaging Camera at right and left ears (T ear Right-IR-TIC, T ear Left-IR-TIC, T ears-IR-TIC) and inner canthi (T inner canthi-IR-TIC).

\begin{tabular}{|c|c|c|c|c|c|c|}
\hline Comparison between Datasets & Sample Size & Mean Values & Standard Deviations & $\mathrm{t}$ & Degrees of Freedom & p-value \\
\hline T Forehead-NCIT/T Forehead-IR-TIC & $30 ; 30$ & $35.7067 ; 34.5900$ & $0.6011 ; 0.8676$ & 5.7949 & 58 & 0.0000 \\
\hline T Forehead-NCIT/T ear Right-IR-TIC & $30 ; 30$ & $35.7067 ; 35.8767$ & $0.6011 ; 0.6355$ & 1.0644 & 58 & 0.2916 \\
\hline T Forehead-NCIT/T ear Left-IR-TIC & $30 ; 30$ & $35.7067 ; 35.6933$ & $0.6011 ; 0.6153$ & 0.0849 & 58 & 0.9326 \\
\hline T Forehead-NCIT/T Ears-IR-TIC & $30 ; 30$ & $35.7067 ; 35.7733$ & $0.6011 ; 0.6158$ & 0.4243 & 58 & 0.6729 \\
\hline T Forehead-NCIT/T inner canthi-IR-TIC & $30 ; 30$ & $35.6400 ; 35.7533$ & $0.6083 ; 0.5582$ & 0.7519 & 58 & 0.4552 \\
\hline T Forehead-IR-TIC/T ear Right-IR-TIC & $30 ; 30$ & $34.5900 ; 35.8767$ & $0.8676 ; 0.6355$ & 6.5530 & 58 & 0.0000 \\
\hline T Forehead-IR-TIC/T ear Left-IR-TIC & $30 ; 30$ & $34.5900 ; 35.6933$ & $0.8676 ; 0.6153$ & 5.6819 & 58 & 0.0000 \\
\hline T Forehead-IR-TIC/T ears-IR-TIC & $30 ; 30$ & $34.5900 ; 35.7733$ & $0.8676 ; 0.6158$ & 6.0920 & 58 & 0.0000 \\
\hline T Forehead-IR-TIC/T inner canthi-IR-TIC & $30 ; 30$ & $34.5900 ; 35.7533$ & $0.8676 ; 0.5582$ & 6.1767 & 58 & 0.0000 \\
\hline
\end{tabular}

T Student's test $(\mathrm{p}<0.01)$

Table 3. Comparisons between the Temperature detected at Forehead with no Contact Infrared Thermometer (T Forehead-NCIT) and Infrared Thermal Imaging Camera (T Forehead-IR-TIC) and Temperature detected with the Infrared Thermal Imaging Camera at right and left ears (T ear Right-IR-TIC, T ear Left-IR-TIC, T ears-IR-TIC) and inner canthi ( $T$ inner canthi-IR-TIC) in males (M) and female (F) patients.

\begin{tabular}{|c|c|c|c|c|c|c|}
\hline Comparison between Datasets & Sample Sizes & Mean Values & Standard Deviations & $\mathbf{t}$ & Degrees of Freedom & p-value \\
\hline $\mathrm{M}$ (T Forehead-NCIT)/F (T Forehead-NCIT) & $16 ; 14$ & $35.5857 ; 35.8125$ & $0.7284 ; 0.4617$ & 1.0321 & 28 & 0.3109 \\
\hline M (T Forehead-IR-TIC)/F (T Forehead-IR-TIC) & $16 ; 14$ & $34.6357 ; 34.5500$ & $0.9187 ; 0.8485$ & 0.2656 & 28 & 0.7925 \\
\hline M (T ear Right IR-TIC)/F (T ear Right-IR-TIC) & $16 ; 14$ & $36.0438 ; 35.6857$ & $0.4690 ; 0.7574$ & 1.5785 & 28 & 0.1257 \\
\hline M (T ear Left-IR-TIC)/F (T ear Left-IR-TIC) & $16 ; 14$ & $35.8313 ; 35.5357$ & $0.3772 ; 0.7398$ & 1.3298 & 28 & 0.1943 \\
\hline M (T ears-IR-TIC)/F ( $\mathrm{T}$ ears-IR-TIC) & $16 ; 14$ & $35.9313 ; 35.5929$ & $0.4143 ; 0.7631$ & 1.5363 & 28 & 0.1357 \\
\hline $\mathrm{M}$ ( $\mathrm{T}$ inner canthi-IR-TIC)/F ( $\mathrm{T}$ inner canthi-IR-TIC) & $16 ; 14$ & $35.8688 ; 35.6214$ & $0.3719 ; 0.7073$ & 1.2210 & 28 & 0.2323 \\
\hline
\end{tabular}

T Student's test $(\mathrm{p}<0.01)$ 


\section{Discussion}

The advent of the novel Coronavirus pandemic had raised many questions relating not only to the effective management of the health emergency but also to establishing the necessary measures to control the spread of the infections when it was understood that lockdown and mandatory quarantine (in case of positivevirus or contact with infected people) could be just drastic temporary measures [37].

Regarding the routine safety measures recommended by the scientific community, in addition to the frequent sanitization of hands and environments and the use of various types of facial masks with different protective filters, great importance was given to controlling body temperature due to the fact one of the most frequent symptoms of SARS-CoV-2 infection is the fever and telephone triage, as we performed in our study, is recommended [4,5].

In the early period of the pandemic, NCITs, already used in medicine, became the recommended devices for use in mass screens since they are fast, easy to use, cheap and do not require direct contact like the common electronic thermometers [8,11]. The use has been very simple and fast in our study too. NCITs became popular in airports, restaurants, offices, hospitals, schools, and all those places with a high turnout. After, the FDA approved in an official document both NCIT and IR-TIC during this pandemic based on the experience reported in the literature about other recent epidemics with febrile symptoms such as Ebola and SARS. While the US and European health authorities have recognized both NCITs and IR-TIC as valid, the Australian authority presented its doubts on the matter by documenting the limitations of these methods of detecting body temperature [9].

The main difference between NCITs and IR-TICs is an NCIT measures surface temperature in a single point. In contrast, a thermal imaging system can measure temperature differences across multiple locations providing a $2 \mathrm{D}$ image where each point corresponds to a temperature value. These devices measure the skin temperature rather than the core temperature, considered necessary for individual fever assessment [9]. Many devices use algorithms to estimate core temperature; however, the difference between core and IR facial measurements can be up to $1.5^{\circ} \mathrm{C}$. The accuracy and reliability of NCITs are under scientific debate, but in a while, they have globally considered the current reference instrument for measuring body temperature despite the lack of wide univocal scientific evidence [10].

Even less, the reliability of IR thermographic systems in recording a real body temperature (useful to establish whether a subject has a fever or not) is scarcely documented too [7,8,10,16,20,24]. During the early spread of Coronavirus, forehead temperature measurement with NCITs became used widely than the measurement at the tympanic point. The tympanic temperature is closer than the forehead temperature to the body's core temperature and gives the most accurate measurements [8,9,11]. With the NCITs, the measurement at the tympanic level was not carried out in compliance with the anti-COVID 19 regulations to not expose the patients involved to any risk [4-6,8-10]. However, an evaluation on a large case series and a comparison between the two types of measurements (skin area of the ears and tympanic area, respectively) would be desirable given the greater reliability of the tympanic temperature compared to that of the forehead.

Studies suggest the emissivity of the tympanic membrane is 1.0, while the emissivity of human skin is between 0.976 and 0.984 [9]. The advantage for which the use of a forehead thermometer has been encouraged is that it does not require changing the probe, like in the tympanic type, and any risk of mutual infection is prevented $[7,8]$.

In our study, the detection of temperature in ear areas with the IR-TIC overcame this limit. Although it is known that tympanic temperature should be more reliable in screening for COVID-19, the forehead 
temperature continues to be measured and, as suggested by other authors, the tympanic temperature should, in any case, be checked when the forehead temperature is already equal to $36^{\circ} \mathrm{C}$ : a difference of almost $2^{\circ} \mathrm{C}$ between the forehead and tympanic temperature could lead to underestimating the presence of fever in the screened subjects $[9,12,24]$. Our results agree in part with these results since the difference between forehead temperatures and ear areas temperatures is around $1.2^{\circ} \mathrm{C}$ when detected both with IR-TIC (statistically significant) while is lower (statistically not significant) when the forehead temperature is recorded with the NCIT.

Many authors suggest the IR-TIC examination as a more reliable temperature detection technique, especially when a short video of the subject is recorded and the highest value of forehead or ear area temperature is extrapolated [24,34]. We followed the same principles and performed forehead and ear area detection of temperature for each subject extrapolating the higher value. In this study, we wanted to test the possibility of recording the measurements taken with the IR-TIC connected to the smartphone in video mode both at the level of the forehead, inner canthi of the eyes and the ear areas, comparing differences of measurements taken with classic NCITs.

Previous authors suggest determining the forehead temperature by the mean values of all the areas into which it is possible to subdivide the forehead [38] but this is not a procedure automatically possible with the device used for this study since the mobile IR-TIC used is able to show only the higher and lower values in a selected area but not mean values of all the areas. Another recent study, assessing the diagnostic effectiveness of standardized IR thermography-based fever screening and evaluating the effect of facial measurement location, concluded the use of IR-TIC is reliable for febrile status determination if properly used [39].

Another study states the most effective approach in temperature detection is to consider the inner canthi the best location, the full-face maximum temperature the best performance and the forehead the less accurate location [24]. Our results agree with this thermographic study since the forehead location in our measurements shows lower values than the inner canthi location (and ear areas location) and the values detected with the NCIT at the forehead, showing a probable less accuracy temperature detection of the front head area.

In general, IR-TICs connected to smartphones provide accurate temperature measurements and their use in medicine for diagnostic purposes is also recently documented [33-35]. They have been used to evaluate post-surgical wounds, tumor lesions assessment, skin inflammation related to pathologies, and ophtalmopathies. The IR-TIC used for this study has features comparable to IR-TICs used in other medical studies [26,27,29,31,33-35].

This kind of IR-TIC is directly connected to a smartphone, where it works thanks to a specific app. Like all the smartphone-TICs, it has the advantage of being easily transportable and versatile and of not requiring fixed support (such as a tripod stand) used for almost all traditional IR-TICs used for medical purposes, so it is necessary that the operator placed at the adequate distance has his own stability during the examination. Pictures or videos taken can be easily downloaded on a personal computer for further analysis or simply opened in its phone gallery. The focusable lens allows adjusting the resolution of the thermographic image based on the distance between the operator and the subject examined. Contrary to what is possible with traditional thermal imaging cameras, in this case, it is not possible for the operator to be placed in a different room from the subject examined [13,21-23], so considering the purposes of the measurements, it is extremely important that the detector operator is adequately distant and protected. 
The thermal sensor and the field of view are comparable to those of more professional thermal imaging cameras [23] and thermal scan used for body temperature detection where the range of detectable temperatures and distance of examination is much smaller. Our results did not show significant differences in body temperature values in males and female subjects independently from the detection of temperature devices and this is in disagreement with another thermographic study on children where girls showed slight upper values of body temperature compared to young boys recorded at rest and after work out [32].

These overall considerations on the results obtained in this study are also encouraged by a recent prepandemic study on children evaluated febrile status during triage, demonstrating how thermographic measurement is a "reliable, comfortable, rapid, non-invasive method for fever screening, particularly in children" [31].

\section{Conclusion}

Temperature values in the auricular area and inner canthi, detected by an infrared thermal imaging camera on a smartphone, are closest to the forehead temperature values detected by the no-contact infrared thermometer. Smartphone thermography, already used successfully in many areas of medical research, is a promising, low-cost and safe tool in the service of pediatric dentistry whose possible applications, in addition to body temperature screening, should be examined.

\section{Authors' Contributions}

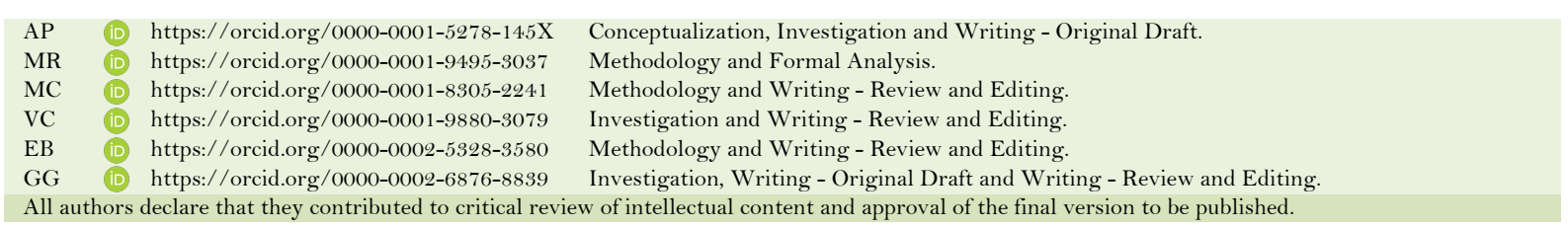

\section{Financial Support}

None.

\section{Conflict of Interest}

The authors declare no conflicts of interest.

\section{Data Availability}

The data used to support the findings of this study can be made available upon request to the corresponding author.

\section{References}

[1] Alsayedahmed HH. COVID-19 Pandemic's precautionary measures had hit the reset button of the quality of life at different aspects. J Infect Dev Ctries 2020; 14(8):812-6. https://doi.org/10.3855/jidc.12943

[2] Villani FA, Aiuto R, Paglia L, Re D. COVID-19 and dentistry: prevention in dental practice, a literature review. Int J Environ Res Public Health 2020; 17(12):4609. https://doi.org/10.3390/ijerph 17124609

[3] Putrino A, Caputo M, Giovannoni D, Barbato E, Galluccio G. Impact of the SARS-Cov2 pandemic on orthodontic therapies: An Italian experience of teleorthodontics. Pesqui Bras Odontopediatria Clín Integr 2020; $20: e 0100$. https://doi.org/10.1590/pboci.2020.140

[4] Pascarella G, Strumia A, Piliego C, Bruno F, Del Buono R, Costa F, et al. COVID-19 diagnosis and management: a comprehensive review. J Intern Med 2020; 288(2):192-206. https://doi.org/10.1111/joim.13091

[5] Guo YR, Cao QD, Hong ZS, Tan YY, Chen SD, Jin HJ, et al. The origin, transmission and clinical therapies on coronavirus disease 2019 (COVID-19) outbreak - an update on the status. Mil Med Res 2020; 7(1):11. https://doi.org/10.1 186/s40779-020-00240-0 
[6] Wiersinga WJ, Rhodes A, Cheng AC, Peacock SJ, Prescott HC. Pathophysiology, transmission, diagnosis, and treatment of coronavirus disease 2019 (COVID-19): A review. J Am Med Assoc 2020; 324(8):749-51. https://doi.org/10.1001/jama.2020.12839

[7] Dell'Isola GB, Cosentini E, Canale L, Ficco G, Dell'Isola M. Noncontact body temperature measurement: uncertainty evaluation and screening decision rule to prevent the spread of COVID-19. Sensors 2021; 21(2):346. https://doi.org/10.3390/s2 1020346

[8] Aw J. The non-contact handheld cutaneous infra-red thermometer for fever screening during the COVID-19 global emergency. J Hosp Infect 2020; 104(4):451. https://doi.org/10.1016/j.jhin.2020.02.010

[9] Chen HY, Chen A, Chen C. Investigation of the impact of infrared sensors on core body temperature monitoring by comparing measurement sites. Sensors 2020; 20(10):2885. https://doi.org/10.3390/s20102885

[10] Crossley B. Troubleshoot it: accuracy of various thermometer types is important to consider during the COVID-19 pandemic. Biomed Instrum Technol 2020; 54(3):228-9. https://doi.org/10.2345/0899-8205-54.3.228

[11] Hakan N, Okumuş N, Aydın M, Küçüközkan T, Tuygun N, Zenciroğlu A. The comparison of temporal temperature measurement method by non-contact infrared thermometer with other body temperature measurement methods. J Behcet Child Hosp 2017; 7:141-6. https://doi.org/10.5222/buchd.2017.141

[12] Vardasca R, Magalhaes C, Marques D, Moreira J, Frade R, Seixas A, et al. Bilateral assessment of body core temperature through axillar, tympanic and inner canthi thermometers in a young population. Physiol Meas 2019; 40(9):094001. https://doi.org/10.1088/1361-6579/ab2af6

[13] Carpes FP, Mello-Carpes PB, Priego Quesada JI, Pérez-Soriano P, Salvador Palmer R, Ortiz de Anda RMC. Insights on the use of thermography in human physiology practical classes. Adv Physiol Educ 2018; 42(3):521-5. https://doi.org/10.1152/advan.00118.2018

[14] Lü Y, He X, Wei ZH, Sun ZY, Chang ST. Ambient temperature-independent dual-band mid-infrared radiation thermometry. Appl Opt 2016; 55(9):2 169-74. https://doi.org/10.1364/AO.55.002169

[15] Wolf A, Pezoa JE, Figueroa M. Modeling and compensating temperature-dependent non-uniformity noise in IR microbolometer cameras. Sensors 2016; 16(7):1121. https://doi.org/10.3390/s16071121

[16] Usamentiaga R, Venegas P, Guerediaga J, Vega L, Molleda J, Bulnes FG. Infrared thermography for temperature measurement and non-destructive testing. Sensors 2014; 14(7):12305-48. https://doi.org/10.3390/s140712305

[17] Zaproudina N, Varmavuo V, Airaksinen O, Närhi M. Reproducibility of infrared thermography measurements in healthy individuals. Physiol Meas 2008; 29(4):515-24. https://doi.org/10.1088/0967-3334/29/4/007

[18] Villa E, Arteaga-Marrero N, Ruiz-Alzola J. Performance assessment of low-cost thermal cameras for medical applications. Sensors 2020; 20(5):1321. https://doi.org/10.3390/s20051321.

[19] Kasprzyk-Kucewicz T, Cholewka A, Bałamut K., Kownacki P, Kaszuba N, Kaszuba M, et al. The applications of infrared thermography in surgical removal of retained teeth effects assessment. J Therm Anal Calorim 2021; 144:13944. https://doi.org/10.1007/s10973-020-09457-6

[20] Negishi T, Abe S, Matsui T, Liu H, Kurosawa M, Kirimoto T, et al. Contactless vital signs measurement system using RGB-thermal image sensors and its clinical screening test on patients with seasonal influenza. Sensors 2020; 20(8):2171. https://doi.org/10.3390/s20082171

[21] Barbosa JS, Amorim A, Arruda M, Medeiros G, Freitas A, Vieira L, et al. Infrared thermography assessment of patients with temporomandibular disorders. Dentomaxillofac Radiol 2020; 49(4):20190392. https://doi.org/10.1259/dmfr.20190392

[22] Endo T, Komatsuzaki A, Miyagawa Y, Kamoda T, Goto S, Koide K, et al. Thermographic assessment of facial temperature in patients undergoing orthognathic surgery. J Oral Sci 2019; 61(2):321-6. https://doi.org/10.2334/josnusd.18-0194

[23] Harshavardhan T, Vijayalaxmi N, Mudavath M, Meesala D. Thermography: A newer diagnostic assessment tool in dentistry. J Mahatma Gandhi Inst Med Sci 2017; 22(2):87-92. https://doi.org/10.4103/jmgims.jmgims_79_15

[24] Zhou Y, Ghassemi P, Chen M, McBride D, Casamento JP, Pfefer TJ, et al. Clinical evaluation of fever-screening thermography: impact of consensus guidelines and facial measurement location. J Biomed Opt 2020; 25(9):097002. https://doi.org/10.1117/1.JBO.25.9.097002

[25] Saxena AK, Willital GH. Infrared thermography: experience from a decade of pediatric imaging. Eur J Pediatr 2008; 167(7):757-64. https://doi.org/10.1007/s00431-007-0583-z

[26] Sanchis-Sánchez E, Salvador-Palmer R, Codoñer-Franch P, Martín J, Vergara-Hernández C, Blasco J, et al. Infrared thermography is useful for ruling out fractures in paediatric emergencies. Eur J Pediatr 2015; 174(4):493-9. https://doi.org/10.1007/s00431-014-2425-0

[27] Blasco JM, Sanchis-Sánchez E, Martín JD, Sanchis E, Salvador-Palmer R, Cibrián R. A Matlab based interface for infrared thermographic diagnosis of pediatric musculoskeletal injuries. Infrared Phys Technol 2016; 76:500-3. https://doi.org/10.1016/j.infrared.2016.04.018

[28] Owen R, Ramlakhan S. Infrared thermography in paediatrics: a narrative review of clinical use. BMJ Paediatr Open 2017; 1(1):e000080 
[29] Owen R, Ramlakhan S, Saatchi R, Burke D. Development of a high-resolution infrared thermographic imaging method as a diagnostic tool for acute undifferentiated limp in young children. Med Biol Eng Comput 2018; 56(6):1115-25. https://doi.org/10.1007/s11517-017-1749-0

[30] Martini G, Cappella M, Culpo R, Vittadello F, Sprocati M, Zulian F. Infrared thermography in children: a reliable tool for differential diagnosis of peripheral microvascular dysfunction and Raynaud's phenomenon? Pediatr Rheumatol 2019; 17(1):68. https://doi.org/10.1186/s12969-019-0371-0

[31] Atas Berksoy E, Bag Ö, Yazici S, Celik T. Use of non contact infrared thermography to measure temperature in children in a triage room. Medicine 2018; 97(5):e9737. https://doi.org/10.1097/MD.0000000000009737

[32] Dębiec-Bak A, Kuligowski T, Skrzek A. Analyzing thermoregulation processes in early school-age girls and boys through thermography. J Therm Anal Colorim 2020; 140:243-51. https://doi.org/10.1007/s10973-019-08843-z

[33] van Doremalen RFM, van Netten JJ, van Baal JG, Vollenbroek-Hutten MMR, van der Heijden F. Infrared 3D thermography for inflammation detection in diabetic foot disease: a proof of concept. J Diabetes Sci Technol 2020; 14(1):46-54. https://doi.org/10.1177/1932296819854062

[34] Kirimtat A, Krejcar O, Selamat A, Herrera-Viedma E. FLIR vs SEEK thermal cameras in biomedicine: comparative diagnosis through infrared thermography. BMC Bioinformatics 2020; 21(Suppl 2):88. https://doi.org/10.1186/s12859-020-3355-7

[35] Minatel Riguetto C, Minicucci WJ, Moura Neto A, Tambascia MA, Zantut-Wittmann DE. Value of infrared thermography camera attached to a smartphone for evaluation and follow-up of patients with graves' ophthalmopathy. Int J Endocrinol 2019; 2019:7065713. https://doi.org/10.1155/2019/7065713

[36] Browne RH. On the use of a pilot sample for sample size determination. Stat Med 1995; 14(17):1933-40. https://doi.org/10.1002/sim.4780141709

[37] Putrino A, Raso M, Magazzino C, Galluccio G. Coronavirus (COVID-19) in Italy: knowledge, management of patients and clinical experience of Italian dentists during the spread of contagion. BMC Oral Health 2020; $20: 200$. https://doi.org/10.1186/s12903-020-01187-3

[38] Ng EY, Kaw GJ, Chang WM. Analysis of IR thermal imager for mass blind fever screening. Microvasc Res 2004; 68(2): 104-9. https://doi.org/10.1016 / j.mvr.2004.05.003

[39] Pannu J. Nonpharmaceutical Measures for pandemic influenza in nonhealthcare settings-international travel-related measures. Emerg Infect Dis 2020; 26(9):2298-9. https://doi.org/10.3201/eid2609.201990 